\title{
The Moderating Effect of Leaders' Experience on Leadership Styles and Crisis Management in the Jordanian Hotel Sector
}

\author{
Raed Hussam Alzoubi ${ }^{1}$ \& Amar Hisham Jaaffar ${ }^{2}$ \\ ${ }^{1}$ College of Graduate Studies, Universiti Tenaga Nasional, Malaysia \\ ${ }^{2}$ Institute of Energy Policy and Research (IEPRe) and College of Business Management and Accounting, Universiti \\ Tenaga Nasional, Malaysia \\ Correspondence: Raed Hussam Alzoubi, College of Graduate Studies, Universiti Tenaga Nasional, Malaysia.
}

Received: July 8, 2020

Accepted: Sepember 8, 2020

Online Published: January 9, 2021

doi:10.5430/ijfr.v12n1p297

URL: https://doi.org/10.5430/ijfr.v12n1p297

\begin{abstract}
Crisis management is vital for hotels to survive in the present competitive business climate in Jordan. Previous research into leadership and crisis management produced inconclusive results. Therefore, the influence of a leader's experience on the relationship between leadership styles and crisis management needed to be further investigated and analyzed. A quantitative study involving a self-administered questionnaire was carried out using respondents in management roles at 3 to 5-star hotels operating in Jordan. The Smart-PLS 3.0 was used to analyze the survey data. Results show that transformational and transactional leadership has a positive and significant relationship with crisis management practice. Furthermore, a leader's experience plays an important role in improving the relationship between a transformational leadership style and crisis management. However, the results show that although, leadership style is important, a leader's experience can be of even greater value if they possess a transformational leadership style. From the perspective of contingency theory, when managing a crisis, the style of leadership is contingent on situational factors and a leader with experience may have an extra advantage in influencing his/her subordinates to practice crisis management.
\end{abstract}

Keywords: crisis management, leadership experience, hotels, transactional leadership, transformational leadership, contingency theory

\section{Introduction}

The hotel sector is reputed to be among the fastest growing sectors in the global economy. It is also considered to be among the top job generating industries due to its labour intensive nature as well as the significant multiplier impact it has on employment in other related sectors. In Jordan, hotels are significantly dependent on tourist arrivals hence tourism is a principal export sector. The hotel industry is also a major player in the tourism sector which has been directly linked to significant foreign exchange earnings (MOTA, 2003). As reported by the Central Bank of Jordan, the tourism sector contributes approximately $10.50 \%$ to the country's gross domestic product (MOTA, 2016). Moreover, tourism generated 2870.9 million JD in 2016 as revenue ( $1 \mathrm{JD}=1.408 \mathrm{USD}$ ), while tourist spending reached 892.9 million JD in the same year (MOTA, 2016). However, 2010-2016 could be considered as a time of crisis for Jordanian tourism with different indicators of sector performance showing a clear decline when compared to the period prior to 2010. By referring to the statistical reports of the Jordanian Ministry of Tourism \& Antiquities for the years 2010-2016, Table 1 shows some of the main indicators relating to Jordanian tourism for 2010-2016. 
Table 1. The main indicators of tourism performance in Jordan for the years 2010-2016

\begin{tabular}{|c|c|c|c|c|c|c|c|}
\hline & \multicolumn{9}{|c|}{ Year } & Arrivals & $\begin{array}{c}\text { Receipts } \\
\text { (JD } \\
\text { Million) }\end{array}$ & $\begin{array}{c}\text { No of } \\
\text { Package } \\
\text { Tourists }\end{array}$ & $\begin{array}{c}\text { No of } \\
\text { Overnight } \\
\text { Tourists }\end{array}$ & $\begin{array}{c}\text { No of } \\
\text { Same } \\
\text { Day } \\
\text { Tourists }\end{array}$ & $\begin{array}{c}\text { No Tourist } \\
\text { Nights }\end{array}$ & $\begin{array}{c}\text { Tourists } \\
\text { Expendi } \\
\text { tures } \\
\text { JD } \\
\text { Million) }\end{array}$ \\
\hline 2010 & $8,078,380$ & 2545.2 & 707,735 & $4,557,024$ & $3,690,112$ & $5,301,639$ & $1,010.5$ \\
\hline 2011 & $6,812,438$ & 2431.5 & 419,571 & $3,959,651$ & $2,852,787$ & $4,638,399$ & 823.9 \\
\hline 2012 & $6,314,250$ & 2883.6 & 446,165 & $4,162,367$ & $2,151,883$ & $5,806,317$ & 811.9 \\
\hline 2013 & $4,136,928$ & 2212.2 & 307,348 & $3,022,192$ & $1,114,736$ & $4,970,581$ & 778.3 \\
\hline 2014 & $5,326,501$ & 3106.6 & 443,226 & $3,989,913$ & $1,336,501$ & $2,019,287$ & 810.7 \\
\hline 2015 & $4,811,352$ & 2886.1 & 300,970 & $3,763,150$ & $1,048,202$ & $1,125,159$ & 823.5 \\
\hline 2016 & $4,778,529$ & 2870.9 & 372,661 & $3,858,439$ & 920,020 & $4,894,237$ & 892.9 \\
\hline
\end{tabular}

Source: (MOTA, 2016)

From the Table 1, it can be seen that there has been a downward trend in tourist arrivals and receipts. These developments are having a catastrophic impact on the hotel industry in Jordan which is in the part of the Middle East that is in the midst of a crisis. Crisis in an organization entails any action and/or failure to act that is not in line with the organization's purposes, its vision, mission and objectives, as well as the success of the organization and its employees, clients or constituents (Seeger \& Ulmer, 2003). A crisis is additionally conceptualized as an unstable time or state of affairs in which there is an impending and/or a decisive change (Aljuhmani \& Emeagwali, 2017). In view of this, crisis management is crucial if hotels are going to survive. Crisis management involves an integrated and all-inclusive effort that organizations can carry out to recognize, comprehend and prevent a crisis, as well as effectively and efficiently managing a crisis that is unavoidable while, at the same time, considering the interests of its stakeholders (Santana, 2004).

Several research scholars such as Woods and King, (2002); Al Khattab and Aldehayyat, (2011); Masa'deh, et al., (2018) have suggested that Jordanian hotels and related service businesses need to adopt effective leadership styles and crisis management strategies in order improve guest services. During a crisis, an organization requires a leader who has: 1) effective decision-making skills, 2) is available and involved and who can motivate good partnerships with stakeholders, 3) good communication skills with stakeholders and external parties, 4) the ability to reassure the public, 5) advocacy skills, 6) effective delegation skills and 7) the skills to effectively coordinate resources and responses (Arifah, Tariq, Rosliza, \&Juni, 2018). More importantly, research scholars such as Boin and McConnell, (2009) have argued that, in a crisis, leaders can experience severe limitations in their efforts to manage it. Reliable and consistent data/information about the situation, or the state of the response network, is often unavailable, hence, a great deal of experience in a leadership position is required to implement appropriate crisis management strategies.

The objective of this paper is to examine the effect of leadership styles on crisis management. It will also evaluate the moderating effect of a leader's experience on the relationship between leadership styles as an independent variable and crisis management as a dependent variable.

\section{Literature Review}

A number of studies have been carried out on leadership styles and their impact on the implementation of crisis management. However, they have not focused on the hotel sector, especially in the midst of a crisis. The following is a brief review of previous studies.

Bass Leadership Theory posits two leadership styles (transactional leadership and transformational leadership) that can improve performance. Transactional leadership behaviour involves the monitoring, controlling, as well as the motivation of employees to achieve organizational goals by rational or economic means (Cummings et al., 2010). Transactional leaders are noted as leaders who focus on the motivation of followers by using rewards or discipline while at the same time, clarifying the kinds of rewards that should be expected for various behaviors (Emery \& Barker, 2007). In times of crisis, proponents of Bass transactional leadership have argued that a 'give and take' situation is applied to crisis management, whereby the leaders elicit followers' involvement in crisis management strategies by anticipating employee needs and then promise the meeting of these needs contingent on their effective performance. However, Bass transformational leadership concentrates on the organizational leader motivating the employees beyond immediate self-interest. These leaders are known to elevate the employees' level of maturity and 
ideals as well as their desire for achievement, self-actualization, and the well-being of others, the organization, and society at large. As a result, Voon, et al. (2011) as well as Jackson, Meyer and Wang (2013) argue that the adoption by managers of transformational leadership behaviours is more satisfying for employees. Transformational leaders tend to be more effective and proactive. They are also known to offer a purpose that transcends short-term goals while focusing on higher order intrinsic needs (Tyssen, Wald \& Spieth, 2014; Kharabsheh et al, 2017; Alzoubi \& Jaaffar, 2020a).

A study conducted by Hater and Bass (1988) observed that transformational leaders are seen to take responsibility for proactivity of performance in the organization, hence they are better suited to instilling better crisis signal detection and preparedness measures in the overall crisis management strategy of the organization. This contributes positively to performance enhancement as they convey a sense of mission, inspire learning experiences, as well as stimulate newer ways of thinking. On the other hand, transactional leaders attain crisis containment and recovery as simply essential by means of the use of contingent rewards or negative feedback.

\subsection{Transformational Leadership Style and Crisis Management}

Crises are usually not predicted or expected, but the contemporary business environment requires that crisis management strategies are always in place in order to forestall whatever crisis event might occur at any time. The contingency theory posits that the success of organizational leadership relates to a specific situation because effective leadership depends, not only on the style of leadership, but on the control of a situation, which in turn, has an influence on the success or failure of leadership in the organization.

Previous studies, for instance, the study by Tsai (2008) in which 300 hotel employees in Finland were surveyed by means of a self-administered questionnaire, found that transformational leadership had a positive effect on employee job satisfaction. The result of this was an improvement in customer outcomes and the circumvention of potential adverse events due to the ability of satisfied employees to deploy behaviours to mitigate the effects of the crisis and execute crisis strategies. The findings of the study also revealed that employees are more satisfied with the transformational leadership style (Tsai, 2008). Moreover, Brown and Arendt (2011) in their quantitative study of employees from 34 hotels in the United States of America found that, in line with transformational leadership style of their supervisors, employees exhibited improved performance in areas that included positive attitudes to warning signals of impending turbulence, involvement in hotel policies that aid damage control as well as crisis prevention, and an unwavering care for hotel property and operational procedures (Brown \& Arendt, 2011). These findings are underpinned by the Contingency Theory which provides insights into the capability of a transformational leader to adjust his leadership style to make important changes relevant to changing environments, situations or conditions such as in crisis circumstances.

Contingency Theory states that the changes made by a leader during changing conditions (such as in a crisis) must be done using the right skills for the right conditions (Arifah, et al., 2018). Moreover, Burns (2003) argues that in crisis conditions, both transformational leaders and followers help each other to advance to a higher level of crisis management.

As a result, the following hypothesis is put forward:

\section{H1: Transformational Leadership has a positive effect on Crisis Management}

\subsection{Transactional Leadership style and Crisis Management}

Transactional leadership style makes use of supervision, organization, and performance monitoring strategies to enhance the performance of organizational employees by means of reward systems as well as punishments. It helps to maintain and sustain already established crisis management protocols and strategies devised by top management. As a result, many business executives are aware of the negative consequences associated with an organizational crisis and focus on communications as well as crisis recovery procedures as a reactive strategy.

However, many neglect the other leadership responsibilities associated with organizational crises. This may result from lack of formal training and on-the-job experiences that prepare executives to learn from previous crises. Executives who employ competencies which are in line with the features of transactional leadership enable their organizations to recover from a crisis and exhibit a complex set of competencies in each of the five phases of crisis management: crisis signal detection, crisis preparation and prevention, crisis containment, crisis recovery, and crisis learning (Wooten \& James, 2008). Kapucu and Ustun (2018) as well as Alzoubi \& Jaaffar, (2020b), found that core transactional leadership competencies have a positive relationship with the effectiveness of crisis management. Moreover, previous studies have been conducted on the different factors affecting employee 'on the job' satisfaction. Contingency Theory describes how the interaction of leadership styles and situations to be managed will indicate 
how effective the leadership is. This model shows the dynamics of the interaction that occurs between the leader who has distinct personal characteristics and motivations, and the group of workers or followers facing specific situations. Hence, contingency theory not just focus on attributing leadership effectiveness to personality alone. This supports the findings of Kapucu and Ustun (2018) which show that during a crisis, task-oriented, people-oriented, and organization-oriented categories of leadership behaviors, as seen in the transactional leadership style, have the greatest impact on crisis management.

As a result, the following hypothesis is put forward:

\section{H2: Transactional Leadership has a positive effect on Crisis Management}

In term of the role of leader's experience on the relationship between leadership style and crisis management, previous study has found that due to lack of experience leaders were reluctant to implement proactive crisis management strategies due to limited expertise and resource that they have (Gomez-Meija et. Al., 2010). The result of that study show that leader's experience have merit in managing crisis. This argument is in line with previous study which have shown that leadership experience improves a leader's performance in a crisis, and that amount of experience is a factor in assessing leadership (Banalieva \& Eddleston, 2011; Sturgis, Shiflett, \& Tanner, 2017). Furthermore, previous study also revealed that leaders with extensive experience might have a large number of followers and have a strong influence on them, thus may make them more proactive in crisis management (Walls $\&$ Beronne, 2015).

As a result, the following hypothesis is put forward:

\section{H3: Leadership experience moderates the relationship between transformational leadership style and crisis management}

H4: Leadership experience moderates the relationship between transactional leadership style and crisis management

\section{Conceptual Model and Research Hypotheses}

In order to specify the research hypotheses targeted in Table, a research structural model was developed for this study. The research structural model is intended to test 4 hypotheses. The hypotheses are: the direct effects of Transformational Leadership (TFL), Transactional Leadership (TSL) on Crisis Management (CSM) which relates to hypotheses $\mathrm{H} 1$ and $\mathrm{H} 2$, while two hypotheses relate to the moderating effect of Leader's Experience (LDE) on the relationship between Transformational Leadership (TFL) and Transactional Leadership (TSL) as the independent variables on Crisis Management (CSM) as the dependent variable (i.e., H3 and H4). 错误!未找到引用源。 illustrates the hypotheses in the research structural model and their relative paths.

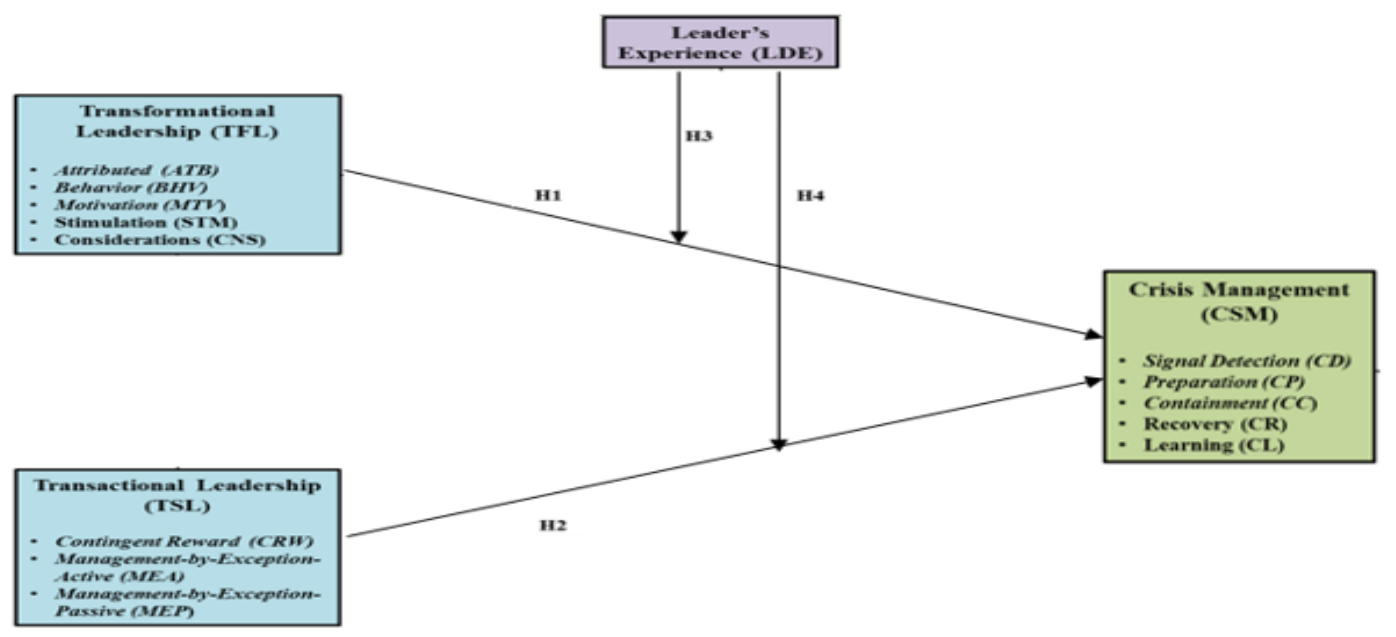

Figure 1. Research Hypotheses in research structural model 


\subsection{Research Hypotheses}

The codes and description of the research hypotheses are represented in Table .

Table 2. Research hypotheses (Codes and descriptions)

\begin{tabular}{lll}
\hline Code & \multicolumn{1}{c}{ Description } & Path \\
\hline Direct Effect Hypotheses & & \\
\hline H1 & $\begin{array}{l}\text { Transformational Leadership (TFL) has a positive effect on Crisis Management } \\
\text { (CSM) }\end{array}$ & TFL $\rightarrow$ CSM \\
H2 & Transactional Leadership (TSL) has a positive effect on Crisis Management (CSM) & TSL $\rightarrow$ CSM \\
\hline Moderation Effect Hypotheses & $\begin{array}{l}\text { Leadership experience moderates the relationship between transformational } \\
\text { leadership style and crisis management }\end{array}$ & LDE*TFL $\rightarrow$ CSM \\
H3 & $\begin{array}{l}\text { Leadership experience moderates the relationship between transactional leadership } \\
\text { style and crisis management }\end{array}$ & LDE*TSL $\rightarrow$ CSM \\
& &
\end{tabular}

\section{Methodology}

This study was both exploratory and explanatory (causal) in design, and a cross sectional time horizon was applied using a self-administered questionnaire survey. The unit of analysis was the hotels in Jordan. The survey was administered to managers and hotel owners of 3-star, 4-star and 5-star hotels in Jordan. It is expected that this category of hotels (3-star to 5-star) have developed crisis management strategies and that the respondents (managers and hotels owners) have the decision making responsibilities in their respective hotels and therefore, are better suited to provide the information needed for the present study. It was also a desired prerequisite that the respondents had occupied their current positions in the hotel sector for more than three years, as this strengthens their experience in crisis management. The sampling frame which contained a list of registered hotels in Jordan (as of 2019) was obtained from the Jordanian Hotel Association. judgmental sampling was used select the hotels taking part in the survey (3-star to 5-star), and the respondents were purposively recruited. The questionnaires were distributed according to the Self-Distribute Management (DOPU) to the Hotel Management for 146 hotels. Overall, 146 questionnaires were distributed and 126 questionnaires were retrieved making a response rate of $86.3 \%$. Out of these 126 questionnaires received, 7 were incompletely filled, leaving a total of 119 valid questionnaires fit for analysis.

\subsection{Research Instrument}

The research instrument utilized in this study (see Table 3) was adapted from previously established measurement scales, but due to contextual differences which can present significant variances, the measures were subjected to content validity with experts ( 5 academic experts and 2 managers of hotels in Jordan), as well as a pilot study in which the internal consistency reliability was tested on the pilot data from 25 respondents (Alkharabsheh, \& Alias, 2018; Aigbogun, Ghazali \& Razali, 2017). The respondents used in the pilot study were excluded from the main study. Moreover, interval scale was used where the constructs of interest were estimated through the respondents' perceptual evaluation on a 5-point Likert-type scale (1- strongly disagree and 5- strongly agree). Also, a back-to back translation was used to translate the questionnaire from the English version to the Arabic version to provide an opportunity for respondents to take part in the survey using either of the two languages (English or Arabic). The results of the reliability test, using Cronbach alpha for internal consistency, revealed that the reliability of the constructs ranged from 0.764 to 0.929 which are all above the 0.7 threshold (Hair, Ringle, \& Sarstedt, 2011).

Table 3. Instrument measures and sources

\begin{tabular}{llcc}
\hline Variables & Indicators & No of items & Sources \\
\hline Transformational & Attributed (ATB) & 4 \\
leadership & Behavior (BHV) & 4 \\
\hline
\end{tabular}




\begin{tabular}{|c|c|c|c|}
\hline & Motivation (MTV) & 4 & \multirow{6}{*}{ Avolio and Bass (2004) } \\
\hline & Stimulation (STM) & 4 & \\
\hline & Considerations (CNS) & 4 & \\
\hline Transactional & Contingent Reward (CRW) & 4 & \\
\hline \multirow[t]{2}{*}{ leadership } & Management-by-Exception-Active (MEA) & 4 & \\
\hline & Management-by-Exception-Passive (MEP) & 4 & \\
\hline \multirow[t]{5}{*}{ Crisis management } & Signal Detection (CD) & 5 & \multirow{5}{*}{ Alkhawlani, et al. (2016) } \\
\hline & Preparation $(\mathrm{CP})$ & 8 & \\
\hline & Containment (CC) & 7 & \\
\hline & Recovery (CR) & 4 & \\
\hline & Learning (CL) & 4 & \\
\hline
\end{tabular}

\subsection{Common Method Bias}

Harman's single-factor test (Hoyle, 1995) was employed to check for common method bias. The results of an un-rotated EFA of all study items revealed that 13 factors in total explained $67.64 \%$ of the variance (Table 4). Given that a single factor solution was not found and a general factor did not account for most of the variance, common method bias did not occur in this study.

Table 4. Results of EFA for Common Method Bias Test (Harman's single-factor test)

\begin{tabular}{ccccccc}
\hline \multirow{2}{*}{ Component } & \multicolumn{3}{c}{ Initial Eigenvalues } & \multicolumn{3}{c}{ Extraction Sums of Squared Loadings } \\
& Total & \% of Variance & Cumulative $\%$ & Total & \% of Variance & Cumulative \% \\
\hline 1 & 24.963 & 32.419 & 32.419 & 24.963 & 32.419 & 32.419 \\
2 & 4.796 & 6.229 & 38.648 & 4.796 & 6.229 & 38.648 \\
3 & 3.419 & 4.440 & 43.087 & 3.419 & 4.440 & 43.087 \\
4 & 2.706 & 3.514 & 46.601 & 2.706 & 3.514 & 46.601 \\
5 & 2.388 & 3.101 & 49.702 & 2.388 & 3.101 & 49.702 \\
6 & 2.141 & 2.781 & 52.483 & 2.141 & 2.781 & 52.483 \\
7 & 1.983 & 2.575 & 55.058 & 1.983 & 2.575 & 55.058 \\
8 & 1.832 & 2.379 & 57.437 & 1.832 & 2.379 & 57.437 \\
9 & 1.784 & 2.317 & 59.754 & 1.784 & 2.317 & 59.754 \\
10 & 1.646 & 2.138 & 61.892 & 1.646 & 2.138 & 61.892 \\
11 & 1.593 & 2.069 & 63.961 & 1.593 & 2.069 & 63.961 \\
12 & 1.460 & 1.896 & 65.857 & 1.460 & 1.896 & 65.857 \\
13 & 1.371 & 1.781 & 67.638 & 1.371 & 1.781 & 67.638 \\
\hline
\end{tabular}

\subsection{Data Analysis}

A total of 119 valid responses were subjected to data analysis. Partial Least Squares (PLS) technique as part of Structural Equation Modelling (SEM) was applied to analyse the causal relationships between the research constructs using the software application Smart-PLS 3.0. The PLS approach was selected due to the exploratory nature of the research (Hair et al., 2011). The two-step approach was utilized in data analysis as suggested by Henseler, Ringle, and Sinkovics (2009). The first step involved the analysis of the measurement model, while the second step tested the structural relationships among the latent constructs. The two-step approach aims at establishing the reliability and 
validity of the measures before assessing the structural relationship of the model.

\section{Results and Findings}

\subsection{Sample Profile}

Table 5 represents the frequencies and percentages of the demographical variables.

Table 5. Sample profile

\begin{tabular}{|c|c|c|}
\hline Description & Frequency & Percentage \\
\hline \multicolumn{3}{|l|}{ Gender } \\
\hline Male & 95 & 79.8 \\
\hline Female & 24 & 20.2 \\
\hline \multicolumn{3}{|l|}{ Current position } \\
\hline Hotel Owner & 0 & 0 \\
\hline General Manager & 14 & 11.8 \\
\hline Deputy General Manager & 20 & 16.8 \\
\hline Department Manager & 85 & 71.4 \\
\hline Other (please specify): & 0 & 0 \\
\hline \multicolumn{3}{|c|}{ Number of years have been working in the current position in the hotel sector. } \\
\hline Less than 3 years & 0 & 0 \\
\hline $3-6$ years & 32 & 26.9 \\
\hline 7-10 years & 16 & 13.4 \\
\hline $11-14$ years & 24 & 20.2 \\
\hline More than 14 years & 47 & 39.5 \\
\hline \multicolumn{3}{|l|}{ Hotel Star Rating } \\
\hline 3 Stars & 65 & 54.6 \\
\hline 4 Stars & 28 & 23.5 \\
\hline 5 Stars & 26 & 21.8 \\
\hline \multicolumn{3}{|c|}{ Number of years of hotel operation } \\
\hline Less than 3 years & 0 & 0 \\
\hline $3-6$ years & 4 & 3.4 \\
\hline $7-10$ years & 23 & 19.3 \\
\hline $11-14$ years & 13 & 10.9 \\
\hline More than 14 years & 79 & 66.4 \\
\hline
\end{tabular}

\subsection{Measurement Model}

Cronbach's alpha, composite reliability (CR), average variance extracted (AVE), convergent validity and discriminant validity were examined.

5.2.1 Reliability and Convergent Validity

Table represents the result of reliability and convergent validity for the measurement model. 
Table 6. Results of reliability and convergent validity for measurement model

\begin{tabular}{|c|c|c|c|c|c|}
\hline Construct & Item & $\begin{array}{c}\text { Factor } \\
\text { Loading }\end{array}$ & $\begin{array}{c}\text { Average } \\
\text { Variance } \\
\text { Extracted } \\
(\mathrm{AVE})^{\mathrm{a}}\end{array}$ & $\begin{array}{l}\text { Composite } \\
\text { Reliability } \\
\qquad(\mathrm{CR})^{\mathrm{b}}\end{array}$ & $\begin{array}{c}\text { Internal } \\
\text { Reliability } \\
\text { Cronbach } \\
\text { Alpha }\end{array}$ \\
\hline \multirow[t]{4}{*}{ Attributed (ATB) } & ATB1 & 0.851 & \multirow[t]{4}{*}{0.692} & \multirow[t]{4}{*}{0.900} & \multirow[t]{4}{*}{0.852} \\
\hline & ATB2 & 0.831 & & & \\
\hline & ATB3 & 0.835 & & & \\
\hline & ATB4 & 0.811 & & & \\
\hline \multirow[t]{4}{*}{ Behavior (BHV) } & BHV1 & 0.792 & \multirow[t]{4}{*}{0.700} & \multirow[t]{4}{*}{0.903} & \multirow[t]{4}{*}{0.857} \\
\hline & BHV2 & 0.831 & & & \\
\hline & BHV3 & 0.885 & & & \\
\hline & BHV4 & 0.835 & & & \\
\hline \multirow[t]{4}{*}{ Motivation (MTV) } & MTV1 & 0.810 & \multirow[t]{4}{*}{0.697} & \multirow[t]{4}{*}{0.902} & \multirow[t]{4}{*}{0.855} \\
\hline & MTV2 & 0.852 & & & \\
\hline & MTV3 & 0.869 & & & \\
\hline & MTV4 & 0.807 & & & \\
\hline \multirow[t]{4}{*}{ Stimulation (STM) } & STM1 & 0.845 & \multirow[t]{4}{*}{0.709} & \multirow[t]{4}{*}{0.907} & \multirow[t]{4}{*}{0.863} \\
\hline & STM2 & 0.857 & & & \\
\hline & STM3 & 0.822 & & & \\
\hline & STM4 & 0.843 & & & \\
\hline \multirow[t]{4}{*}{ Considerations (CNS) } & CNS1 & 0.839 & \multirow[t]{4}{*}{0.719} & \multirow[t]{4}{*}{0.911} & \multirow[t]{4}{*}{0.870} \\
\hline & CNS2 & 0.875 & & & \\
\hline & CNS3 & 0.830 & & & \\
\hline & CNS4 & 0.847 & & & \\
\hline \multirow[t]{4}{*}{ Contingent Reward (CRW) } & CRW1 & 0.813 & \multirow[t]{4}{*}{0.694} & \multirow[t]{4}{*}{0.901} & \multirow[t]{4}{*}{0.853} \\
\hline & CRW2 & 0.829 & & & \\
\hline & CRW3 & 0.845 & & & \\
\hline & CRW4 & 0.844 & & & \\
\hline \multirow{4}{*}{$\begin{array}{l}\text { Management-by-Exception-Acti } \\
\text { ve (MEA) }\end{array}$} & MEA1 & 0.844 & 0.735 & 0.917 & 0.880 \\
\hline & MEA2 & 0.868 & & & \\
\hline & MEA3 & 0.858 & & & \\
\hline & MEA4 & 0.858 & & & \\
\hline Management-by-Exception-Passi & MEP1 & 0.848 & 0.706 & 0.905 & 0.861 \\
\hline ve (MEP) & MEP2 & 0.883 & & & \\
\hline & MEP3 & 0.827 & & & \\
\hline & MEP4 & 0.800 & & & \\
\hline Signal Detection (CD) & CD1 & 0.847 & 0.715 & 0.926 & 0.900 \\
\hline & $\mathrm{CD} 2$ & 0.825 & & & \\
\hline & CD3 & 0.859 & & & \\
\hline & CD4 & 0.880 & & & \\
\hline & CD5 & 0.816 & & & \\
\hline Preparation $(\mathrm{CP})$ & CP1 & 0.754 & 0.576 & 0.905 & 0.877 \\
\hline & $\mathrm{CP} 2$ & 0.748 & & & \\
\hline & $\mathrm{CP} 3$ & 0.745 & & & \\
\hline & $\mathrm{CP} 4$ & 0.741 & & & \\
\hline
\end{tabular}




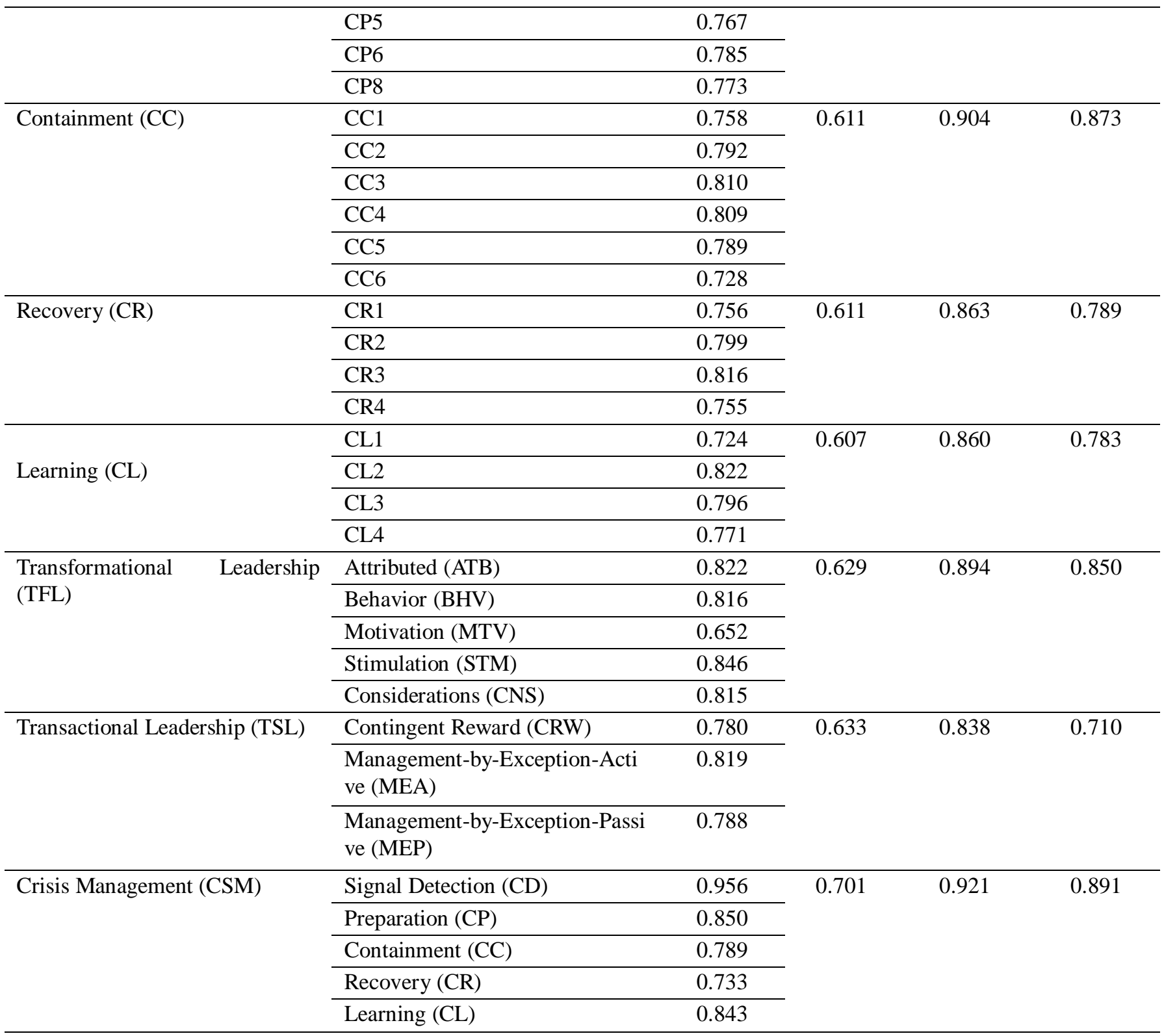

As shown in the Table 6, the results of assessing the standardized loadings of the items showed that the factor loadings of CP7 and CC7 were 0.118 and 0.157 respectively. Both values were below the cut-off point of 0.6 (Hair et al., 2011). Thus, both items were deleted. The revised model revealed standardized factor loadings were above the threshold of 0.6 ( 0.652 to 0.956$)$. Table shows that the AVE was above the threshold of 0.5 for all constructs (Nunnally \& Bernstein, 1994). The composite reliability values ranged from 0.838 to 0.926 which exceeded the recommended threshold of 0.6 for all constructs (Bagozzi \& Yi, 1988). The Cronbach's alpha values ranged from 0.710 to 0.900 which were above the threshold of 0.7 (Nunnally \& Bernstein, 1994). Therefore, the achieved values of the measurement model for all constructs were considered sufficiently error-free.

\subsubsection{Discriminant Validity}

Discriminant validity was examined by following HTMT Discriminant criteria (Henseler et al., 2015). Based on the Table 7, all the HTMT of the latent construct were below 0.90. This results show that all measurement used for this study don't have any interrelation and acceptable for further analysis. 
Table 7. Results of HTMT discriminant criteria

\begin{tabular}{llll}
\hline & CSM & TFL & TSL \\
\hline CSM & & & \\
TFL & 0.680 & & \\
TSL & 0.863 & 0.881 & \\
\hline
\end{tabular}

\subsection{Structural Models}

\subsubsection{Direct Effects of Constructs}

In the structural model, the direct effects of Transformational Leadership (TFL) and Transactional Leadership (TSL) on Crisis Management (CSM) were examined. These effects refer to hypotheses H1 and H2. The result of the hypothesized direct effects is shown in the Table 8.

Table 8. Examining results of hypothesized direct effects of the variables

\begin{tabular}{lccccccc}
\hline \multicolumn{1}{c}{ Path Shape } & $\begin{array}{c}\text { Path } \\
\text { Coefficient }\end{array}$ & $\begin{array}{c}\text { Standard } \\
\text { Deviation }\end{array}$ & T-value & P-value & F-squared & $\begin{array}{c}\text { Effect } \\
\text { Size }\end{array}$ & $\begin{array}{c}\text { Hypothesis } \\
\text { Result }\end{array}$ \\
\hline TFL $\rightarrow$ CSM & $0.226^{*}$ & 0.097 & 2.336 & 0.020 & 0.054 & Small & H1) Supported \\
\hline TSL $\rightarrow$ CSM & $0.530^{* * *}$ & 0.066 & 8.014 & 0.000 & 0.295 & Medium & H2) Supported \\
\hline${ }^{*} \mathrm{p}<0.05, * * \mathrm{p}<0.01, * * * \mathrm{p}<0.001$ & & & & & &
\end{tabular}

The values of adjusted $\mathrm{R}^{2}$ values for Crisis Management (CSM) were 0.488 . This indicates that $48.8 \%$ of variations in Crisis Management (CSM) are explained by its two predictors (TFL and TSL). The values of the predictive relevance $\left(\mathrm{Q}^{2}\right)$ for Crisis Management $(\mathrm{CSM})$ was 0.292 which is greater than zero, hence, the model exhibits acceptable fit and high predictive relevance (Chin, 2010).

\subsubsection{Moderation Effects of Leader's Experience (LDE)}

The moderating effects of Leader's Experience (LDE) were examined as presented in Table 9. In addition, the path coefficient was used to evaluate the contribution of each interaction term on the dependent variable (Crisis management).

Table 9. Moderation effects of Leader's Experience (LDE)

\begin{tabular}{cccccccc}
\hline Path Shape & $\begin{array}{c}\text { Path } \\
\text { Coefficient }\end{array}$ & $\begin{array}{c}\text { Standard } \\
\text { Deviation }\end{array}$ & T-value & P-value & F-squared & $\begin{array}{c}\text { Effect } \\
\text { Size }\end{array}$ & $\begin{array}{c}\text { Hypothesis } \\
\text { Result }\end{array}$ \\
\hline LDE*TFL $\rightarrow$ CSM & $0.215^{*}$ & 0.102 & 2.111 & 0.035 & 0.048 & Small & H3) Supported \\
\hline LDE*TSL $\rightarrow$ CSM & -0.078 & 0.082 & 0.954 & 0.340 & 0.007 & $\begin{array}{c}\text { No effect } \\
\text { size }\end{array}$ & H4) Rejected \\
\hline$* \mathrm{p}<0.05, * * \mathrm{p}<0.01, * * * \mathrm{p}<0.001$ & & & & & &
\end{tabular}

As shown in Table 9, the interaction term of Leader's Experience (LDE) with Transformational Leadership (TFL) had significant effects on Crisis Management (CSM) as the p-value was lower than the standard significance level of 0.05. These results demonstrated that Leader's Experience (LDE) moderates the effects of Transformational Leadership (TFL) on Crisis Management (CSM). Therefore, hypotheses H3 was supported. Furthermore, the value of F-squared was 0.048, showing that the effect size of Leader's Experience (LDE) interaction with Transformational Leadership (TFL) on Crisis Management (CSM) was small.

Furthermore, the effect of Leader's Experience (LDE) interaction with Transactional Leadership (TSL) on Crisis 
Management $(\mathrm{CSM})$ was not statistically significant; Coefficient Path $=-0.078$, T-value $=0.954, \mathrm{p}$-value $=0.340$. This result indicated that Leader's Experience (LDE) could not moderate the relationship between Transactional Leadership (TSL) and Crisis Management (CSM). Thus, the hypothesis H4 was rejected. Furthermore, the value of F-squared was 0.007, indicating the effect size of Leader's Experience (LDE) interaction with Transactional Leadership (TSL) on Crisis Management (CSM) was not considerable.

\section{Conclusion}

The findings from this study reveal that the effect of transformational leadership and transactional leadership as independent variables of crisis management was statistically significant. Moreover, it could be concluded that the leader's experience positively moderates the relationship between transformational leadership and crisis management. This shows that leaders with considerable experience have a stronger influence on his/her followers in crisis management. Nevertheless, for a leader with a transactional leadership style, no moderation effect was found. This shows that, in relation to transactional leadership style, the experience of the leader may have a less important effect on followers as long as they receive their rewards if they carry out the orders of their leader in crisis management.

The findings confirm Bass Transformational Leadership Theory by showing that leadership experience is a very important factor influencing followers in the execution of crisis management strategies. In relation to Contingency Theory, this study indicated that leadership style may have a strong influence on crisis management. Nevertheless, it depends on the 'turbulence' of the environment. If a leader already provides clear strategies for crisis management for his/her followers, the transactional leadership style might be the most beneficial style. However, if the leader implements crisis management on an ad-hoc basis, the transformational leadership style, coupled with the experience of the leader, will have the advantage.

Practically speaking, this study provides insights for the hotel industry in Jordan in terms of what are the crucial characteristics for a leader managing a crisis. Based on the findings, it appears that transactional leadership has a strong influence on crisis management. It shows that leaders need to conduct continuous training sessions for their followers regarding crisis management practices. Rewards and recognition can be one of the important motivational strategies that can make followers prepare for crisis management - this they can do by practicing all five stages of crisis management. However, as hotel finance performance may be badly affected by a crisis, hotel leaders may have limited means for rewarding their followers. Therefore, the transformative style of leadership, plus the experience of the leader, may become a value added asset for the hotel industry when facing an unexpected crisis such as a global pandemic like Covid-19 that has affected more than 170 countries across the globe. It is suggested that hotels need to develop future leaders (talent management) which possess crisis management competencies.

This study has some limitations which include the following: Firstly, it should be noted that the research was carried out within a specific industry (hotel industry), and in one country (Jordan), however, replications in other contexts would increase confidence of the research findings, hence, this provides future researchers with an opportunity to carry out a comparative analysis with the results of this study. Secondly, in collecting hotel information, this study relied on cross-sectional data as well as subjective responses only. Thus, it is suggested to future researchers to supplement this with a longitudinal study as well as some form of objective data as this might provide more robust information. Moreover, future researchers can also focus on other leadership styles not included in this study. Also, future studies related to crisis management, rather than leaders being the target population, such studies can be carried out from the perspective of employees, showing how employee perceive crisis management in their company.

\section{References}

Aigbogun, O., Ghazali, Z., \& Razali, R. (2017). The Impact of Regulatory Function on Supply Chain Resilience: Reliability of Measurement Scales. Global Business and Management Research: An International Journal, 9(1s), 524-531

Aldehayyat, J. S., Al Khattab, A. A., \& Anchor, J. R. (2011). The use of strategic planning tools and techniques by hotels in Jordan. Management Research Review. https://doi.org/10.1108/01409171111117898

Aljuhmani, H. Y., \& Emeagwali, O. L. (2017). The roles of strategic planning in organizational crisis management: The case of Jordanian banking sector. International Review of Management and Marketing, 7(3).

Alkharabsheh, O. H., \& Alias, R. B. (2018). The Mediating Effect of Organisation Culture on the Relationship between Authentic Leadership and Turnover Intention in Jordanian Public Hospitals. Journal of Economic \& Management Perspectives, 12(3). https://doi.org/10.2139/ssrn.3012101

Alkhawlani, M. A. S., Haderi, S. M. A., bin Bohari, A. M., Ahmed, F. B., \& Rahim, N. F. A. (2016). Charisma 
Leadership an Important Determinant for the Crisis Management. International Journal of Business and Social Science, 7(9), 126-136.

Alkhawlani, M. A. S. (2016). The Impact of Leadership Styles on Crisis Management: A Study at Yemen Public and Private Institutions. Universiti Utara Malaysia Thesis.

Alzoubi, R. H. M., \& Jaaffar, A. H. (2020). Leadership Styles, Crisis Management, and Hotel Performance: A Conceptual Perspective of the Jordanian Hotel Industry. Journal of Critical Reviews, 7(10), 556-562.

Alzoubi, R. H., \& Jaaffar, A. H. (2020). The mediating effect of crisis management on leadership styles and hotel performance in Jordan. Int. J. Financ. Res, 11, 384-397. https://doi.org/10.5430/ijfr.v11n4p384

Arifah, A. R., Tariq, M., Rosliza, A. M., \&Juni, M. H. (2018). Leadership Theories in Disease Outbreak Management. International Journal of Public Health and Clinical Sciences, 5(2), 1-16.

Bagozzi, R. P., \& Yi, Y. (1988). On the evaluation of structural equation model. Journal of Academy of Marketing Science. 16(1), 74-94. https://doi.org/10.1007/BF02723327

Banalieva, E. R., \& Eddleston, K. A. (2011). Home-region focus and performance of family firms: The role of family vs non-family leaders. Journal of International Business Studies, 42(8), 1060-1072. https://doi.org/10.1057/jibs.2011.28

Boin, A. (2009). The new world of crises and crisis management: Implications for policymaking and research. Review of Policy research, 26(4), 367-377. https://doi.org/10.1111/j.1541-1338.2009.00389.x

Brown, E. A., \& Arendt, S. W. (2011). Perceptions of Transformational Leadership Behaviors and Subordinates' Performance in Hotels. Journal of Human Resources in Hospitality and Tourism, 10(1), 45. https://doi.org/10.1080/15332845.2010.500205

Burns, M. J. (2003). Transforming leadership. New York, NY: Atlantic Monthly.

Chin, W. W. (2010). How to write up and report PLS analyses. Handbook of partial least squares (pp. 655-690). Springer. https://doi.org/10.1007/978-3-540-32827-8_29

Cummings, G. G., MacGregor, T., Davey, M., Lee, H., Wong, C. A., Lo, E., ... \& Stafford, E. (2010). Leadership styles and outcome patterns for the nursing workforce and work environment: a systematic review. International Journal of Nursing Studies, 47(3), 363-385. https://doi.org/10.1016/j.ijnurstu.2009.08.006

Emery, C. R., \& Barker, K. J. (2007). The effect of transactional and transformational leadership styles on the organizational commitment and job satisfaction of customer contact personnel. Journal of Organizational Culture, Communications and Conflict, 11(1), 77.

Fornell, C., \& Larcker, D. F. (1981). Evaluating structural equation models with unobservable variables and measurement error. Journal of Marketing Research, 18(1), 39-50. https://doi.org/10.1177/002224378101800104

Gomez-Mejia, L. R., Makri, M., \&Larraza-Kintana, M. (2010). Diversification decisions in family-controlled firms. Journal of Management Studies, 47(2), 223-252. https://doi.org/10.1111/j.1467-6486.2009.00889.x

Hair, J. F., Ringle, C. M., \&Sarstedt, M. (2011). PLS-SEM: Indeed a silver bullet. The Journal of Marketing Theory and Practice, 19(2), 139-152. https://doi.org/10.2753/MTP1069-6679190202

Hair Jr, J. F., Sarstedt, M., Hopkins, L., \&Kuppelwieser, V. G. (2014). Partial least squares structural equation modeling (PLS-SEM). European Business Review. https://doi.org/10.1016/j.jfbs.2014.01.002

Hater, J. J., \& Bass, B. M. (1988). Superiors' evaluations and subordinates' perceptions of transformational and transactional leadership. Journal of Applied psychology, 73(4), 695. https://doi.org/10.1037/0021-9010.73.4.695

Henseler, J., Ringle, C. M., \& Sarstedt, M. (2015). A New Criterion for Assessing Discriminant Validity in Variance-based Structural Equation Modeling. Journal of the Academy of Marketing Science, 43(1), 115-135. https://doi.org/10.1007/s11747-014-0403-8

Henseler, J., Ringle, C. M., \&Sinkovics, R. R. (2009). The Use of Partial Least Squares Path Modeling In International Marketing. New Challenges to International Marketing. https://doi.org/10.1108/S1474-7979(2009)0000020014

Hoyle, R. H. (1995). The Structural Equation Modeling Approach: Basic Concepts and Fundamental Issues. Sage, Thousand Oaks, CA.

Jackson, T. A., Meyer, J. P., \& Wang, X. H. (2013). Leadership, commitment, and culture: A meta-analysis. Journal 
of Leadership \& Organizational Studies, 20(1), 84-106. https://doi.org/10.1177/1548051812466919

Kharabsheh, O. H., Alias, R., \& Ismail, M. (2017). The mediating effect of organisation culture on transformational leadership and turnover intention in Jordanian public hospitals. International Journal of Business \& Management Science, 7(2), 237-260. https://doi.org/10.2139/ssrn.3012101

Kapucu, N., \& Ustun, Y. (2018). Collaborative crisis management and leadership in the public sector. International Journal of Public Administration, 41(7), 548-561. https://doi.org/10.1080/01900692.2017.1280819

Kline, R. B. (2010). Principles and practice of structural equation modeling. The Guilford Press.

Masa'deh, R. E., Alananzeh, O., Tarhini, A., \&Algudah, O. (2018). The effect of promotional mix on hotel performance during the political crisis in the Middle East. Journal of Hospitality and Tourism Technology, 9(1), 33-49. https://doi.org/10.1108/JHTT-02-2017-0010

MOTA. (2003). National Tourism Strategy (2004-2010). Retrieved from http://www.tourism.jo/Contents/National_StrategiesAr.aspx

MOTA. (2016). Statistical Bulletins. Retrieved from http://www.mota.gov.j

Nunnally, J. C., \& Bernstein, I. H. (1994). Psychometric Theory. McGraw-Hill, New York.

Santana, G. (2004). Crisis management and tourism: Beyond the rhetoric. Journal of Travel \& Tourism Marketing, 15(4), 299-321. https://doi.org/10.1300/J073v15n04_05

Seeger, M. W., \& Ulmer, R. R. (2003). Explaining Enron: Communication and responsible leadership. Management Communication Quarterly, 17(1), 58-84. https://doi.org/10.1177/0893318903253436

Sturgis, K., Shiflett, B., \& Tanner, T. (2017). Do leaders' experience and concentration area influence school performance?. Administrative Issues Journal, 7(1), 9. https://doi.org/10.5929/2017.7.1.8

Tsai, C. W. (2008). Leadership style and employee's job satisfaction in international tourist hotels. In Advances in Culture, Tourism and Hospitality Research (pp. 293-332). Emerald Group Publishing Limited. https://doi.org/10.1016/S1871-3173(08)02005-3

Tyssen, A. K., Wald, A., \& Heidenreich, S. (2014). Leadership in the context of temporary organizations: A study on the effects of transactional and transformational leadership on followers' commitment in projects. Journal of Leadership \& Organizational Studies, 21(4), 376-393. https://doi.org/10.1177/1548051813502086

Voon, M. L., Lo, M. C., Ngui, K. S., \&Ayob, N. B. (2011). The influence of leadership styles on employees' job satisfaction in public sector organizations in Malaysia. International Journal of Business, Management and Social Sciences, 2(1), 24-32.

Walls, J. L., \&Berrone, P. (2015). The power of one to make a difference: How informal and formal CEO power affect environmental sustainability. Journal of Business Ethics, 1-16. https://doi.org/10.5465/ambpp.2015.40

Woods, R. H., \& King, J. Z. (2002). Leadership and management in the hospitality industry. Educational Inst of the Amer Hotel.

Wooten, L. P., \& James, E. H. (2008). Linking crisis management and leadership competencies: The role of human resource development. Advances in Developing Human Resources, 10(3), 352-379. https://doi.org/10.1177/1523422308316450

\section{Copyrights}

Copyright for this article is retained by the author(s), with first publication rights granted to the journal.

This is an open-access article distributed under the terms and conditions of the Creative Commons Attribution license (http://creativecommons.org/licenses/by/4.0/). 